\title{
Effect of PFA on Strength and Water Absorption of Mortar
}

\author{
Gingos, G.S. ${ }^{1}$, Mohamed Sutan, N. ${ }^{2}$
}

\begin{abstract}
Partial replacement of cement by mineral admixtures or pozzolans can possibly improve the durability of mortar which directly related to its water absorption. Pulverized Fuel Ash (PFA) is one of the pozzolans that is locally available. Laboratory studies have been conducted on mortar mixes of $0.3 \mathrm{w} / \mathrm{c}, 0.4 \mathrm{w} / \mathrm{c}$ and $0.5 \mathrm{w} / \mathrm{c}$ ratios with 10\%, 20\% and 30\% PFA replacements. Mortar cubes were tested to determine their water absorption rates and compressive strengths as they mature. Amount of PFA replacements in the mortar has significant effects on the strength development and water absorption rate of the mortar. Results shows that $20 \%$ PFA mortars of $0.5 \mathrm{w} / \mathrm{c}$ ratio is the best mix to reduced rate of water absorption and achieved higher compressive strength.
\end{abstract}

Keywords: Mortar, Pulverized Fuel Ash (PFA), Water Absorption Test, Compressive Strength

\section{INTRODUCTION}

$\mathrm{M}$ ortar basically consists of cement, sand and water. Ordinary Portland Cement (OPC) plays a very important role in mortar as binder. Due to its increasing energy consumption and high Carbon Dioxide $\left(\mathrm{CO}_{2}\right)$ emission from its production, alternative binding materials are needed to partially replace OPC. Mortar with cement replacement of mineral admixtures or pozzolan is called modified mortar. The use of partial cement replacement such as pozzolanic materials can improve the durability of the mortar produced. Pulverized Fuel Ash (PFA) is one of the pozzolanic materials widely used as cement replacement to produce high durability mortar [1][2].

Durability of mortar is directly related to its water absorption. The higher water absorbed by mortar the less durable it becomes. Water absorption of a mortar specimen is measured by drying the specimen to a constant mass, immersing it in water, and measuring the increase in mass as a percentage of dry mass. It is one of the important properties that determine the durability of mortars. Good mortar mix has water absorption well below $10 \%$ by mass. Factors such as type of materials used, additives, temperature and length of exposure can affect the amount of water absorbed. Water absorption can also influence the strength of mortar.

Previous studies indicated that low-calcium fly ash (ASTM Class F) improved the interfacial zone microstructure [3]. Computer simulation studies predicted that replacing $20 \%$ of cement with fly ash with smaller particles size resulted in higher interfacial strength than that of control Portland cement paste [4]. Previous studies also showed that PFA reduced the porosity of concrete hence contributed to the higher concrete strength [5]. In order to contribute further to the current knowledge in PFA cement replacement in mortar, a laboratory study was carried out to investigate on any possibility of waterproof effects of PFA in mortar and its contribution to mortar strength. 


\section{EXPERIMENTAL PROGRAM}

\section{Materials and specimens preparation}

Materials used in this study are commercially available Ordinary Portland Cement (OPC) equivalent to ASTM Type 1 cement, a commercially available fly ash equivalent to ASTM Type F fly ash and normal grade river sand [6]. Mortar mixes of water-to-cement ratio (W/C) of 0.3, 0.4 and 0.5 were prepared. PFA replaced cement at levels of $10 \%, 20 \%$ and $30 \%$ by mass. The dimension of mortar cubes was $100 \times 100 \times 100 \mathrm{~mm}$. All mortars were removed from the moulds after 24 hours casting and then dry cured. Compressive strength and absorption rate of mortars were determined at age of 1, 7, 14, 21 and 28 days.

\section{Water Absorption Test}

Water absorption test is a measure of the capillary forces exerted by the pore structure causing fluid to be drawn into the body of the material [4]. The amount of water absorbed by mortar mixes depends on the water tightness or waterproofness of the mixes. All mixes were subjected to water absorption test at the end of curing period of 1, 7, 14, 21 and 28 days after demoulding. They were taken from the curing tank 2 days before the test and later oven dried at $100 \pm 5^{\circ} \mathrm{C}$ for 7 days until a constant mass was achieved. Each mix was then weighed. The samples were covered with wax, except the bottom area before they were immersed in trays containing water. The reason of covering the cube with wax is to prevent air from entering the void during immersing process, since the cube is not fully soak in water, but only about $30-35 \mathrm{~mm}$ of water level. The start time was immediately recorded. After 7 days, the mixes were removed from the tank, shook to remove bulk of the water, and dried with a cloth as fast as possible to remove all free water on the surface. They were then weighed again. The measured water absorption by each mix was expressed as the increase in the mass as a percentage of the oven dry mass.

\section{Compressive Strength Test}

All mixes were subjected to compressive strength test at the end of curing period of $1,7,14$, 21 and 28 days after demoulding. This test was carried out to determine the maximum compressive load it can carry per unit area. Since strength of mortar was directly related to the structure of hydrated cement paste, this test was important not only to determine the strength development of the mortar specimen, but also the quality of the mortar specimen. A good mortar specimen should achieve the targeted mean strength at the end of 28 days [2].

The experimental program can be summarized in the flow chart as shown in Figure 1.

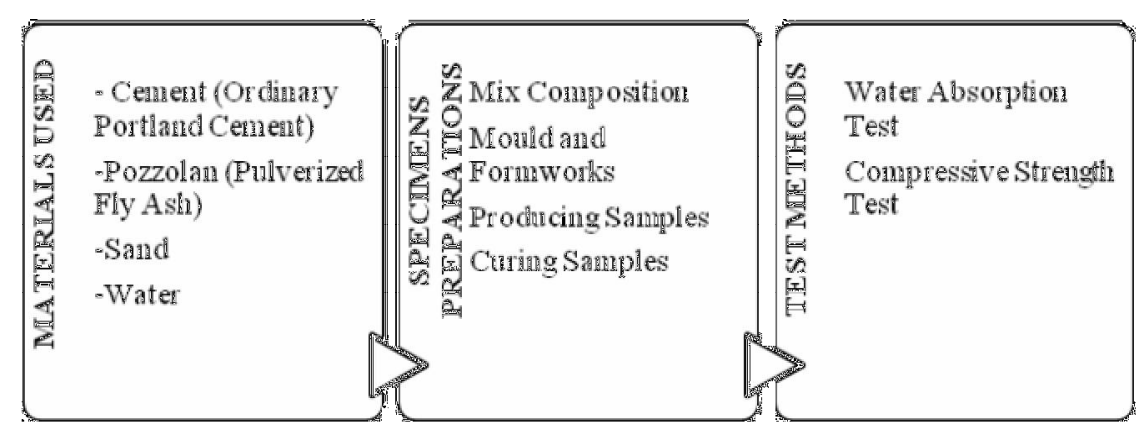

Figure 1: Flow Chart of the Experimental Program 


\section{RESULTS AND ANALYSIS}

\section{Water Absorption Test}

Figure 2 and 3 show the same trend of water absorption rate for all 4 mixes. It shows that $10 \%$ PFA mix had the highest absorption rate compares to other mortar mixes. The other mixes had almost equal water absorption rate. $20 \%$ PFA mix had almost constant water absorption rate for the whole 28 day test. 20\% PFA mix and 30\% PFA mix shows almost the same trend which is relatively small changes in water absorption rate.

Figure 4 shows that $0.5 \mathrm{w} / \mathrm{c}$ has the lowest absorption rate in all mixes comparing to $0.3 \mathrm{w} / \mathrm{c}$ and $0.4 \mathrm{w} / \mathrm{c}$ ratios. Overall results show that control mixes had highest water absorption percentile compare to the other mixes particularly at day 14 . At day 28 , for $0.5 \mathrm{w} / \mathrm{c}$ ratio the more cement replaced with PFA the less the rate of water absorption.

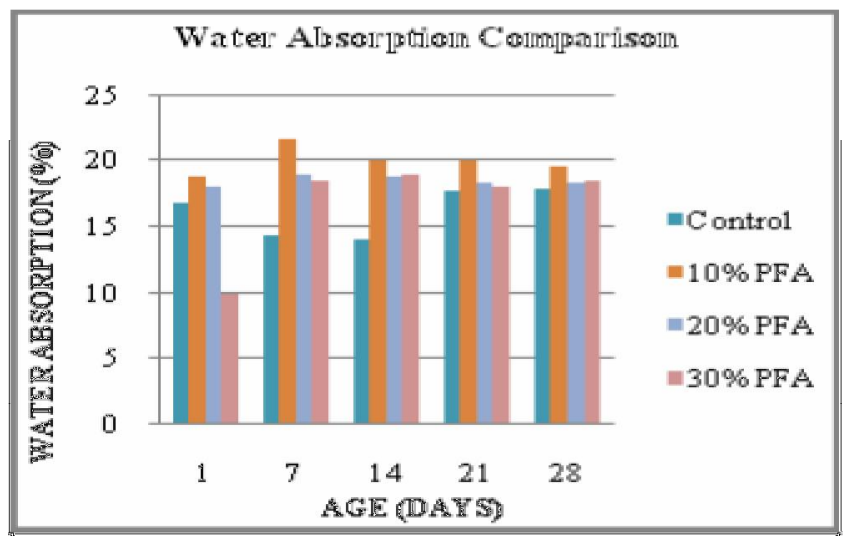

Figure 2: Water absorption for $0.3 \mathrm{w} / \mathrm{c}$ ratio

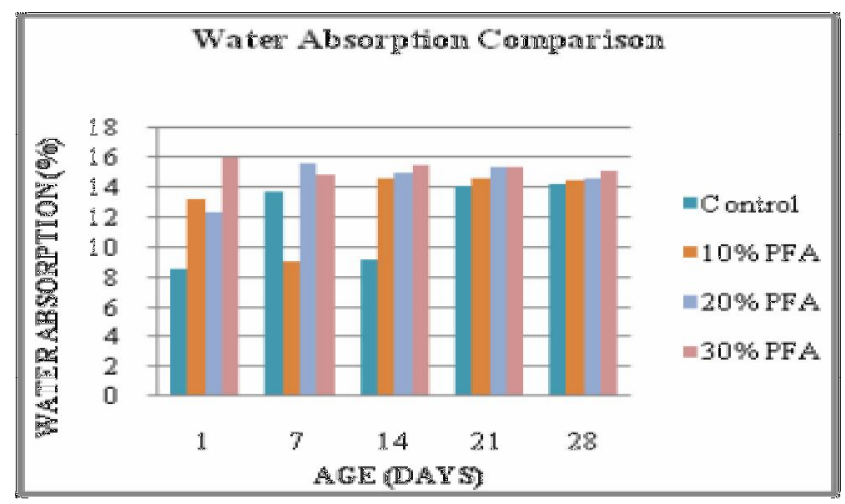

Figure 3: Water absorption for $0.4 \mathrm{w} / \mathrm{c}$ ratio 


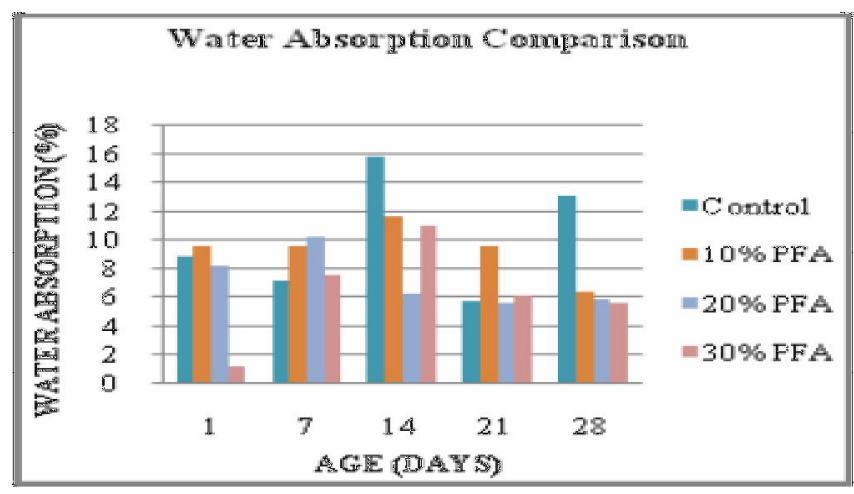

Figure 4: Water absorption for $0.5 \mathrm{w} / \mathrm{c}$ ratio

\section{Compressive Strength Test}

Figure 5 shows almost the same compressive strength at day 1 for all mixes relatively. Control mix shows constant increase whereas sample 20\% PFA and 30\% PFA show uneven development in strength. 10\% PFA mix increased sharply in strength for the first 14 days.

Figure 6 shows that 20\% PFA mix and 30\% PFA mix have a similar linear increment trend in strength development. Meanwhile control mix has slow development in strength in the beginning and achieved high strength at the end of 28 days. 10\% PFA mix has sharp increases in strength development in the first 7 days

Figure 7 shows a different trend in the strength development as compared to the previous mixes with $0.3 \mathrm{w} / \mathrm{c}$ and $0.4 \mathrm{w} / \mathrm{c}$ ratios. Control $\mathrm{mix}$ achieved the highest final strength at 28 days, showing sharp increase in strength for the first 14 days and the last 21 to 28 days. $10 \%$ PFA mix and 20\% PFA mix behave almost similarly which is sharp increase in the first 7 days and a slow strength development afterwards. Whereas for 30\% PFA mix, a linear trend can be seen as constant strength development is achieve.

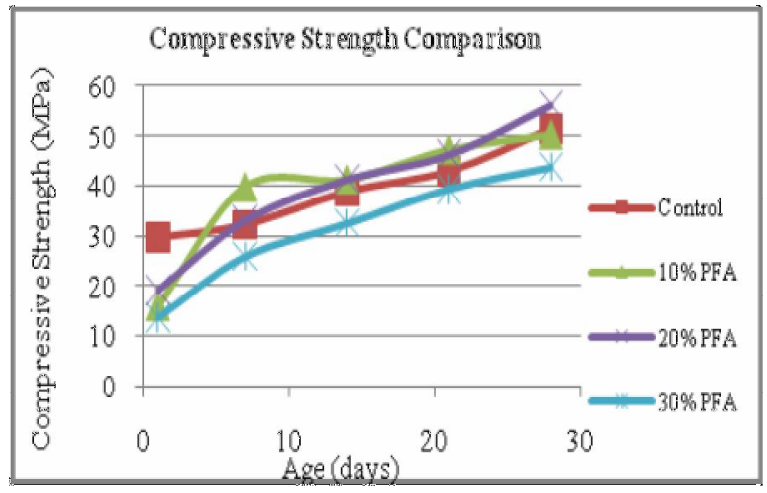

Figure 5: Compressive strength for $0.3 \mathrm{w} / \mathrm{c}$ ratio

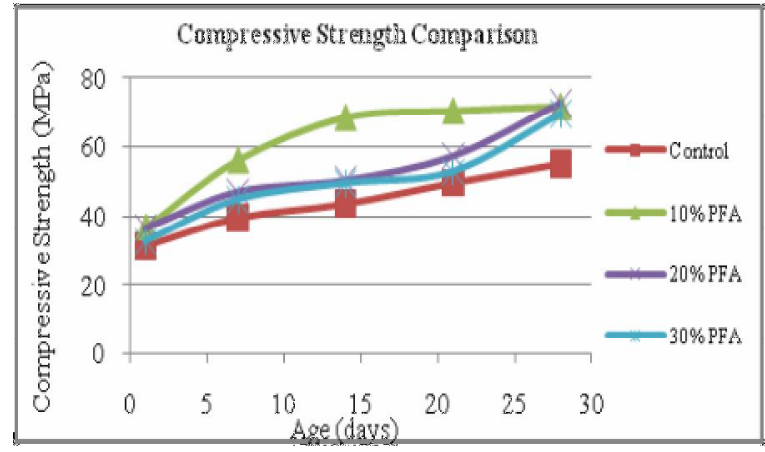

Figure 6: Compressive strength for $0.4 \mathrm{w} / \mathrm{c}$ ratio 


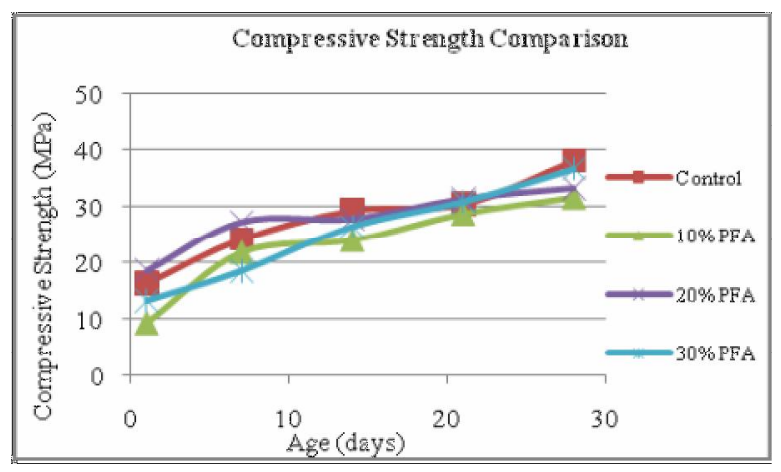

Figure 7: Compressive strength for $0.5 \mathrm{w} / \mathrm{c}$ ratio

\section{CONCLUSIONS}

The effects of replacing cement with PFA to the compressive strength and absorption rate of mortar were investigated. The compressive strength and absorption rate of mortar with $10 \%, 20 \%$ and $30 \%$ PFA cement replacements and of $0.3 \mathrm{w} / \mathrm{c}, 0.4 \mathrm{w} / \mathrm{c}$ and $0.5 \mathrm{w} / \mathrm{c}$ ratios were compared to control mortar. The following conclusions that can be drawn based from the results are:

1. $0.4 \mathrm{w} / \mathrm{c}$ ratio shows significant effects on the compressive strength of mortar at the age of 28 days.

2. $20 \%$ PFA replacement mortar of $0.5 \mathrm{w} / \mathrm{c}$ ratio shows higher compressive strength than the control mortar.

3. Water absorptions of PFA mortars of $0.5 \mathrm{w} / \mathrm{c}$ ratio at 28 days were much lower as compared to control mortar.

4. $20 \%$ PFA mortars of $0.5 \mathrm{w} / \mathrm{c}$ ratio is the best mix to reduced rate of water absorption.

\section{ACKNOWLEDGEMENT}

The authors would like to express their sincere gratitude to UNIMAS and to everyone who involved directly and indirectly to make this a success.

\section{REFERENCES}

[1]W.S. Langley, G.G. Carette, V.M. Malhotra, Structural concrete incorporating high volumes of ASTM Class F fly ash, ACI Materials J86 (1989) 507-514.

[2]C.S. Poon, L. Lam, Y.L. Wong, A study on high strength concrete prepared with large volumes of low calcium fly ash, submitted to Cement and Concrete Research (1999).

[3]G. Carette, A. Bilodeau, R.L. Chevrier, V.M. Malhotra, Mechanical properties of concrete incorporating high volumes of fly ash from sources in the U. S., ACI Materials J 90 (1993) 535-544.

[4]D.P. Bentz, E.J. Garboczi, Simulation studies of the effects of mineral admixtures on the cement paste-aggregate interfacial zone, ACI Materials J 88 (1991) 518-529.

[5]C.S. Poon, L. Lam, Y.L. Wong, Effects of fly ash and silica fume on interfacial porosity, Journal of Materials in Civil Engineering ASCE 11 (1999) 197-205.

[6]ASTM C 618, Standard specification for coal fly ash and raw or Calcined natural Pozzolan for use as a mineral admixture in concrete, ASTM C 618-97, Annual Book ASTM Stand.04.02 (1997) 294 296. 